\title{
Safety of bronchoscopy in patients with malignant hematologic disorders
}

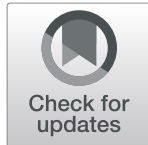

Hironori Uruga ${ }^{1,2,3^{*}} \mathbb{D}$, Toshitaka Sato ${ }^{1,4 \dagger}$, Aya Nishida ${ }^{5,6+}$, Naoyuki Uchida ${ }^{5}$, Masanori Tsuji ${ }^{5}$, Shuhei Moriguchi ${ }^{1}$, Yui Takahashi', Kazumasa Ogawa', Kyoko Murase1, Shigeo Hanada 1,2, Hisashi Takaya ${ }^{1,2+}$, Atsushi Miyamoto 1,2, Nasa Morokawa ${ }^{1,2}$, Muneyoshi Kimura ${ }^{7}$, Hideki Araoka ${ }^{3,7}$, Rumiko Tsuchihashi ${ }^{5}$, Yuki Asano-Mori ${ }^{5}$, Atsushi Wake ${ }^{3,5,6}$, Shuichi Taniguchi, $i^{3,5}$ and Kazuma Kishi, ${ }^{1,2,3,8}$

\begin{abstract}
Background: Factors affecting the safety of bronchoscopy in patients with malignant hematologic disorders have not been well described. We evaluated the safety of bronchoscopy and describe factors affecting its complication rate in such patients.

Methods: Between January 2009 and December 2018, 316 bronchoscopies in 282 patients with malignant hematologic disorders and pulmonary infiltrates were performed at our institution. The bronchoscopic procedure used and its complications were evaluated.

Results: The most common underlying disease was acute myeloid leukemia (134/282 patients, 47.5\%). Platelet transfusion was performed the day before or the day of bronchoscopy in $42.4 \%$, supplemental oxygen was administered before the procedure in $23.1 \%$, and midazolam was used in $74.4 \%$. Thirty-five bronchoscopies (11.1\%) were complicated by hemoptysis and 7 patients developed pneumothorax, 4 of whom required thoracic drainage. Two patients $(0.6 \%)$ were intubated within $48 \mathrm{~h}$ of the procedure and prolonged oxygen desaturation ( $>48 \mathrm{~h}$ ) occurred in 3.8\%. Multivariate analysis showed that only use of midazolam significantly reduced the risk of prolonged oxygen desaturation (hazard ratio $0.28,95 \%$ confidence interval $0.09-0.85, p=0.03$ ). Transbronchial lung biopsy significantly increased the risk of hemoptysis (hazard ratio 10.40, 95\% confidence interval 4.18-25.90, $p=0.00$ ), while use of midazolam significantly reduced the risk (hazard ratio $0.31,95 \%$ confidence interval $0.14-0.73, p=0.01$ ).
\end{abstract}

Conclusions: Bronchoscopy is relatively safe in patients with malignant hematologic disorders. Caution and judicious use of sedatives may improve the patient's procedural tolerance and lower complications.

Keywords: Bronchoscopy, Acute myeloid leukemia, Myelodysplastic syndrome, Malignant lymphoma, Hematopoietic stem cell transplantation, Midazolam

\footnotetext{
* Correspondence: uruga.hironori@gmail.com

${ }^{\dagger}$ Hironori Uruga, Toshitaka Sato, Aya Nishida and Hisashi Takaya contributed equally to this work.

'Department of Respiratory Medicine, Respiratory Center, Toranomon

Hospital, Tokyo, Japan

${ }^{2}$ Department of Respiratory Medicine, Toranomon Hospital Kajigaya,

Kawasaki, Kanagawa, Japan

Full list of author information is available at the end of the article
}

(c) The Author(s). 2020 Open Access This article is licensed under a Creative Commons Attribution 4.0 International License, which permits use, sharing, adaptation, distribution and reproduction in any medium or format, as long as you give appropriate credit to the original author(s) and the source, provide a link to the Creative Commons licence, and indicate if changes were made. The images or other third party material in this article are included in the article's Creative Commons licence, unless indicated otherwise in a credit line to the material. If material is not included in the article's Creative Commons licence and your intended use is not permitted by statutory regulation or exceeds the permitted use, you will need to obtain permission directly from the copyright holder. To view a copy of this licence, visit http://creativecommons.org/licenses/by/4.0/ The Creative Commons Public Domain Dedication waiver (http://creativecommons.org/publicdomain/zero/1.0/) applies to the data made available in this article, unless otherwise stated in a credit line to the data. 


\section{Background}

Pulmonary complications occur in up to $40-60 \%$ of patients with hematologic diseases and have a considerable influence on morbidity and mortality [1]. These complications include infiltration of underlying disease, opportunistic infections, and various pulmonary infiltrates after hematopoietic stem cell transplantation (HSCT), such as idiopathic pneumonia syndrome. Several studies have demonstrated the utility of bronchoscopy in patients with hematologic disorders [2-6], but the factors affecting the safety of bronchoscopy in such patients have not been well described. Here, we evaluated the safety of bronchoscopy at our institution and its complication rate with the aim of elucidating these factors.

\section{Methods}

\section{Subjects}

The institutional review board of Toranomon hospital approved this study (No. 1845). This retrospective study involved patients with malignant hematologic disorders and pulmonary infiltrates who underwent bronchoscopy between January 2009 and December 2018 in a fully equipped endoscopy room in the Department of Respiratory Medicine, Toranomon Hospital, Tokyo, Japan. Bronchoscopies performed in another ward or in the intensive care unit were excluded from the analysis. The need for bronchoscopy was discussed at weekly multidisciplinary team meetings that included hematologists, infectious diseases specialists, and pulmonologists. Bronchoscopy was contraindicated in patients with severe disseminated intravascular coagulation or bleeding tendency. The bronchoscopic procedure used and its complications were evaluated.

\section{Bronchoscopy procedure}

Chest computed tomography was performed using an Aquilion 16 or 64 system (Toshiba Medical Systems, Otawara, Japan), and platelet transfusion was performed for patients with platelet count $\leq 20 \times 10^{3} / \mu$ l before bronchoscopy whether we conducted transbronchial lung biopsy (TBLB) or not. The bronchoscopic procedures were performed using a $4.9-\mathrm{mm}$ bronchoscope (LTF-260; Olympus, Tokyo, Japan). All patients inhaled $5 \mathrm{~mL}$ nebulized $1 \%$ lidocaine solution before the procedure, and lidocaine was squirted in the airways during the procedure. Use of midazolam for sedation during bronchoscopy at our institution was started primarily from the beginning of 2011, which was in the middle of the study period. We administered midazolam $0.03 \mathrm{mg} /$ $\mathrm{kg}$ intravenously before bronchoscopy and usually added $0.01 \mathrm{mg} / \mathrm{kg}$ once or twice during the procedure as needed. Before and after starting to use midazolam, there was no change in bronchoscopist skill or in the approach to patients and overall patient care in the periprocedural period. All bronchoscopies were oral and all procedures were performed by pulmonologists. Oxygen was trans nasally supplied during procedure, if necessary. Bronchoalveolar lavage was performed using 100-150 $\mathrm{mL}$ of normal saline at room temperature and bronchial washing was performed with $10-50 \mathrm{~mL}$ of saline. All patients were placed in the supine position for at least $1 \mathrm{~h}$ after biopsy before undergoing chest radiography. The attending physician then evaluated the severity of pneumothorax and the need for placement of a chest tube.

\section{Statistical analysis}

Oxygen desaturation was defined as worsening of oxygen level compared with that at the time of entering the endoscopy room. Prolonged oxygen desaturation was defined as an oxygen level continuously below baseline for more than $48 \mathrm{~h}$. Univariate analysis was performed using Fisher's exact test and the Mann-Whitney $U$ test and multivariate analysis using multiple logistic regression. Variables with a $p$-value $<0.2$ in the univariate analysis were entered into the multivariate analysis by the variable increase method. All statistical analyses were performed used SPSS statistical software (version 18.0, IBM Corp., Armonk, NY).

\section{Results}

A total of 207 men and 75 women of median age 61 years were included in this study. Bronchoscopy was performed twice in 30 patients and 3 times in 2 patients, giving a total of 316 bronchoscopies in 282 patients. The most common underlying disease was acute myeloid leukemia (AML) including myelodysplastic syndromes (MDS)-overt AML $(n=134,47.5 \%)$. One hundred and thirty-two patients had undergone HSCT (cord blood transplantation, $n=69$; unrelated transplantation $[n=$ $35]$ or related $[n=1]$ bone marrow transplantation; autologous $[n=15]$ or related $[n=12]$ peripheral blood stem cell transplantation). Median platelet count was 91, $000 / \mu \mathrm{L}(3000-568,000)$ in all patients, $126,000 / \mu \mathrm{L}$ $(9000-561,000)$ in patients who underwent TBLB and $64,000 / \mu \mathrm{L}(3000-568,000)$ in those who did not undergo TBLB. Platelet transfusion was performed the day before or the day of the bronchoscopy in 134 procedures (42.4\%). Median neutrophil count was $2840 / \mu \mathrm{L}$. Supplemental oxygen was administered before bronchoscopy at a rate of $0.5-6 \mathrm{~L} / \mathrm{min}$ in 73 bronchoscopies (23.1\%). Bronchial washing was included in 201 bronchoscopies (63.6\%), bronchoalveolar lavage in 104 (32.9\%), TBLB in 125 (39.6\%), bronchial curettage in $6(1.9 \%)$, and endobronchial ultrasound-guided transbronchial needle aspiration in $2(0.6 \%)$. Pethidine was used in 261 bronchoscopies (82.6\%), midazolam in 235 (74.4\%), and atropine sulfate in 291 (92.1\%).

Thirty-five bronchoscopies (11.1\%) were complicated by hemoptysis and 7 patients developed pneumothorax, 
4 of whom required thoracic drainage. There were no severe cardiovascular complications such as arrhythmia and hypotension requiring vasopressor. Two patients $(0.6 \%)$ were intubated within $48 \mathrm{~h}$ of the procedure. The first patient was intubated on the day after the procedure and died the following month; the second patient was intubated just after the procedure and underwent extubation the following day (Table 1). The oxygen desaturation data are summarized in Fig. 1. Prolonged oxygen desaturation $(>48 \mathrm{~h}$ ) occurred after 12 of the 316 bronchoscopies (3.8\%). Oxygen desaturation did not recover in 5 of these 12 patients and was ultimately fatal. The data for these 12 patients are summarized in Table 1 . Hemoptysis was found in 3 of the 12 patients, but none developed pneumothorax. Oxygen desaturation recovered in 7 patients (including 2 with organizing pneumonia, 2 with invasion of underlying disease, and 1 with pneumocystis pneumonia). The 5 patients with no recovery of oxygen desaturation included 2 patients with aspergillosis and 2 with cytomegalovirus pneumonia.

Univariate and multivariate analyses were performed to identify risk factors for prolonged oxygen desaturation ( $>48 \mathrm{~h}$ ) after bronchoscopy. Factors identified as statistically significant in univariate analysis were platelet count $\leq 20 \times 10^{3} / \mu$ l, TBLB not performed, and midazolam not administered (Table 2). The multivariate analysis showed that only use of midazolam significantly reduced the risk of prolonged oxygen desaturation (hazard ratio 0.28, 95\% confidence interval 0.09-0.85, $p=0.03$; Table 2).

Univariate analysis for hemoptysis shows TBLB was the only significant risk factor. Multivariate analysis showed that TBLB significant increased the risk for hemoptysis (hazard ratio 10.40, 95\% confidence interval 4.18-25.90, $p=0.00$; Table 3), while use of midazolam significantly reduced the risk (hazard ratio 0.31, 95\% confidence interval 0.14-0.73, $p=0.01$; Table 3).

\section{Discussion}

We performed 316 bronchoscopies in 282 patients with malignant hematologic disorders and pulmonary infiltrates over a period of 10 years. Acute myeloid leukemia accounted for about half of the underlying diseases. Two patients were intubated within $48 \mathrm{~h}$ of the procedure and 12 experienced prolonged oxygen desaturation. Multivariate analysis showed that use of midazolam significantly reduced the risk of prolonged oxygen desaturation by approximately a quarter, whereas TBLB increased the risk of hemoptysis approximately 10-fold.

Table 1 Summary of 12 patients with prolonged oxygen desaturation (> $48 \mathrm{~h}$ ) after bronchoscopy

\begin{tabular}{|c|c|c|c|c|c|c|c|c|c|}
\hline Case & $\begin{array}{l}\text { Underlying } \\
\text { disease }\end{array}$ & Sedation & $\begin{array}{l}\text { Platelet } \\
(\times 103 / \mu \mathrm{l})\end{array}$ & $\begin{array}{l}\text { Oxygen before } \\
\text { bronchoscopy }\end{array}$ & $\begin{array}{l}\text { Oxygen after } \\
\text { bronchoscopy }\end{array}$ & Method & $\begin{array}{l}\text { Clinical } \\
\text { diagnosis }\end{array}$ & Hemoptysis & Outcome \\
\hline 1 & ALL & $\begin{array}{l}\text { Fentanyl } \\
3 \mathrm{mg} / \text { hour }\end{array}$ & 37 & RA & $1 \mathrm{~L} / \mathrm{min}$ & $\begin{array}{l}\text { Bronchial } \\
\text { wash }\end{array}$ & Aspergillosis & - & $\begin{array}{l}\text { Died after } \\
2 \text { months }\end{array}$ \\
\hline 2 & AML & Peth $27.2 \mathrm{mg}$ & 20 & RA & $1 \mathrm{~L} / \mathrm{min}$ & $\begin{array}{l}\text { Bronchial } \\
\text { wash }\end{array}$ & Unknown & - & Died after 3 weeks \\
\hline 3 & AML & Peth $20.9 \mathrm{mg}$ & 9 & RA & $4 \mathrm{~L} / \mathrm{min}$ & $\begin{array}{l}\text { Bronchial } \\
\text { wash }\end{array}$ & CMV pneumonia & + & Died after 9 days \\
\hline 4 & ALL & Peth $18.5 \mathrm{mg}$ & 110 & $6 \mathrm{~L} / \mathrm{min}$ & $12 \mathrm{~L} / \mathrm{min}$ & $\begin{array}{l}\text { Bronchial } \\
\text { wash }\end{array}$ & CMV pneumonia & - & $\begin{array}{l}\text { Intubated, died } \\
\text { after } 1 \text { month }\end{array}$ \\
\hline 5 & AML/MDS & $\mathrm{HH} 25 \mathrm{mg}$ & 48 & $1 \mathrm{~L} / \mathrm{min}$ & $1 \mathrm{~L} / \mathrm{min}$ & $\begin{array}{l}\text { Bronchial } \\
\text { wash }\end{array}$ & Aspergillosis & + & Died after 13 days \\
\hline 6 & AML & Peth $25 \mathrm{mg}$ & 161 & $2 \mathrm{~L} / \mathrm{min}$ & $8 \mathrm{~L} / \mathrm{min}$ & $\begin{array}{l}\text { Bronchial } \\
\text { wash }\end{array}$ & OP & - & Recovered \\
\hline 7 & AML/MDS & $\begin{array}{l}\text { Mid } 1.5 \mathrm{mg} \text {, } \\
\text { Peth } 28 \mathrm{mg}\end{array}$ & 38 & RA & $2 \mathrm{~L} / \mathrm{min}$ & $\begin{array}{l}\text { Bronchial } \\
\text { wash }\end{array}$ & $\begin{array}{l}\text { Underlying } \\
\text { disease }\end{array}$ & - & Recovered \\
\hline 8 & AML & Peth $27.3 \mathrm{mg}$ & 25 & RA & RA & $\begin{array}{l}\text { Bronchial } \\
\text { wash }\end{array}$ & $\mathrm{OP}$ & - & Recovered \\
\hline 9 & ALL & Peth $21 \mathrm{mg}$ & 384 & RA & $10 \mathrm{~L} / \mathrm{min}$ & BAL, TBLB & $\begin{array}{l}\text { Pneumocystis } \\
\text { pneumonia }\end{array}$ & + & $\begin{array}{l}\text { Intubated, } \\
\text { recovered }\end{array}$ \\
\hline 10 & AML & $\begin{array}{l}\text { Mid } 1.2 \mathrm{mg} \\
\text { Peth } 27.0 \mathrm{mg}\end{array}$ & 14 & $1 \mathrm{~L} / \mathrm{min}$ & $3 \mathrm{~L} / \mathrm{min}$ & $\begin{array}{l}\text { Bronchial } \\
\text { wash }\end{array}$ & Unknown & - & Recovered \\
\hline 11 & AML & $\begin{array}{l}\text { Mid } 1.5 \mathrm{mg} \\
\text { Peth } 26.3 \mathrm{mg}\end{array}$ & 98 & RA & $3 \mathrm{~L} / \mathrm{min}$ & $\begin{array}{l}\text { Bronchial } \\
\text { wash }\end{array}$ & $\begin{array}{l}\text { Underlying } \\
\text { disease }\end{array}$ & - & Recovered \\
\hline 12 & AML & $\begin{array}{l}\text { Mid } 2 \mathrm{mg} \\
\text { Peth } 31.5 \mathrm{mg}\end{array}$ & 171 & RA & $5 \mathrm{~L} / \mathrm{min}$ & $\begin{array}{l}\text { Bronchial } \\
\text { wash }\end{array}$ & Aspergillosis & - & Recovered \\
\hline
\end{tabular}

ALL Acute lymphocytic leukemia, AML Acute myeloid leukemia, BAL Bronchoalveolar lavage, CBT Cord blood transplantation, CMV Cytomegalovirus, $H H$ Hydroxyzine hydrochloride, MDS Myelodysplastic syndromes, Mid Midazolam, OP Organizing pneumonia, Peth Pethidine, RA Room air, rBMT Related BMT, $r P B S T$ Related peripheral blood stem cell transplantation, TBLB Transbronchial lung biopsy, $u B M T$ Unrelated bone marrow transplantation 


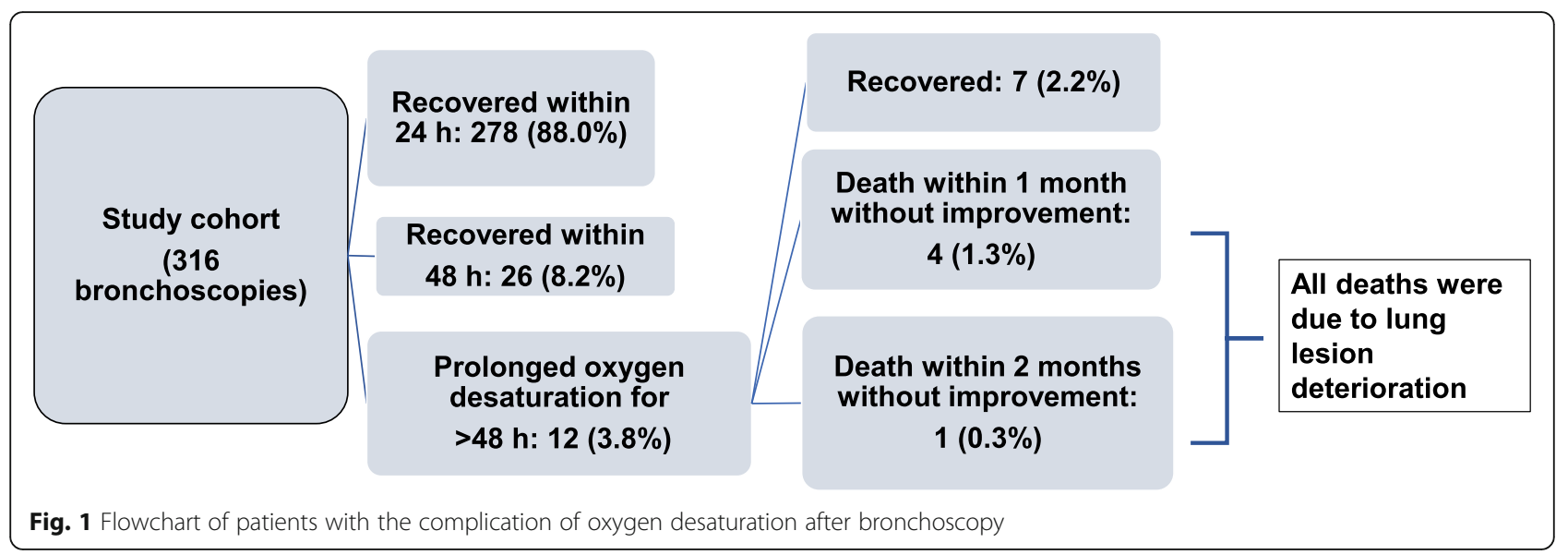

A review by Harris et al. [6] identified the following complications of bronchoscopy after HSCT: bleeding (1.5-15\%), pneumothorax (0-4\%), and hypoxemia. Yanik et al. [7] retrospectively assessed 444 patients who underwent bronchoscopy after HSCT and reported that complications developed in $3.6 \%$ of patients; $1.8 \%$ had low oxygen saturation, $1.7 \%$ had bleeding, $0.2 \%$ had low blood pressure, and $2 \%$ required mechanical ventilation within 2 days. Our results are consistent with the previous studies. In our study, 4 of 5 patients in whom oxygen desaturation did not recover had severe infection (aspergillosis or cytomegalovirus pneumonia), suggesting that their prolonged oxygen desaturation was likely a consequence of severe lung disease rather than a complication of bronchoscopy.
Our study identified use of midazolam to be a favorable factor for reducing the risk of prolonged oxygen desaturation. Midazolam was used as the main agent for sedation during bronchoscopy at our institution starting from the beginning of 2011. Sedation with midazolam improves patients' comfort and increases their ability to tolerate the procedure without significant hemodynamic changes or respiratory depression [8-10]. Our study shows that the results of the previous studies are applicable to bronchoscopy in patients with malignant hematologic disorders.

Hemoptysis occurred in 35 patients but was not serious except in 1 patient who was intubated just after bronchoscopy and had prolonged oxygen desaturation. TBLB significantly increased the risk of hemoptysis,

Table 2 Risk factors for prolonged oxygen desaturation

\begin{tabular}{|c|c|c|c|c|c|}
\hline Characteristic & $\begin{array}{l}\text { Prolonged oxygen } \\
\text { desaturation group } \\
(n=12)\end{array}$ & $\begin{array}{l}\text { Improvement } \\
\text { group }(n=304)\end{array}$ & $\begin{array}{l}p \text { value of } \\
\text { univariate } \\
\text { analysis }\end{array}$ & $\begin{array}{l}p \text { value in } \\
\text { multivariate } \\
\text { analysis }\end{array}$ & $\begin{array}{l}\text { Hazard ratio } \\
(95 \% \mathrm{Cl})\end{array}$ \\
\hline Age $\leq 70$ years & 0 & 39 & 0.37 & & \\
\hline Sex (male/female) & $10 / 2$ & $225 / 79$ & 0.74 & & \\
\hline AML and MPAL & 9 & 153 & 0.09 & 0.19 & \\
\hline Platelet count $(\leq 20 \times 103 / \mu \mathrm{l})$ & 3 & 26 & 0.05 & 0.12 & \\
\hline Platelet transfusion & 7 & 127 & 0.26 & & \\
\hline Neutrophil count $(\leq 500)$ & 2 & 61 & 1.00 & & \\
\hline Within 180 days from BMT except PBSCT & 3 & 58 & 0.71 & & \\
\hline Inhalation of oxygen ( $\geq 5 \mathrm{~L} / \mathrm{min}$ ) & 1 & 5 & 0.10 & 0.31 & \\
\hline Bronchial wash & 9 & 192 & 0.55 & & \\
\hline BAL & 3 & 101 & 0.76 & & \\
\hline TBLB & 2 & 119 & 0.14 & 0.15 & \\
\hline Use of midazolam & 5 & 230 & 0.01 & 0.03 & $0.28(0.09-0.85)$ \\
\hline Use of pethidine & 10 & 251 & 1.00 & & \\
\hline Use of atropine sulfate & 10 & 281 & 0.24 & & \\
\hline
\end{tabular}

Bold indicates statistical significance

$A M L$ Acute myeloid leukemia, BAL Bronchoalveolar lavage, BMT Bone marrow transplantation;

MPAL Mixed phonotype acute leukemia, PBST Peripheral blood stem cell transplantation, TBLB Transbronchial lung biopsy 
Table 3 Risk factors for hemoptysis

\begin{tabular}{|c|c|c|c|c|c|}
\hline Characteristic & $\begin{array}{l}\text { Patients with } \\
\text { hemoptysis }(n=35)\end{array}$ & $\begin{array}{l}\text { Patients without } \\
\text { hemoptysis }(n=281)\end{array}$ & $\begin{array}{l}p \text { value of } \\
\text { univariate } \\
\text { analysis }\end{array}$ & $\begin{array}{l}p \text { value in } \\
\text { multivariate } \\
\text { analysis }\end{array}$ & $\begin{array}{l}\text { Hazard ratio } \\
(95 \% \mathrm{Cl})\end{array}$ \\
\hline Age $\leq 70$ years & 3 & 36 & 0.60 & & \\
\hline Sex (male/female) & $29 / 6$ & $206 / 75$ & 0.22 & & \\
\hline AML and MPAL & 17 & 145 & 0.74 & & \\
\hline Platelet count $(\leq 20 \times 103 / \mu \mathrm{l})$ & 1 & 28 & 0.23 & 0.69 & \\
\hline Platelet transfusion & 17 & 117 & 0.43 & & \\
\hline Neutrophil count $(\leq 500)$ & 9 & 54 & 0.36 & & \\
\hline Within 180 days from BMT except PBSCT & 4 & 57 & 0.21 & & \\
\hline Inhalation of oxygen ( $\geq 5 \mathrm{~L} / \mathrm{min})$ & 0 & 6 & 1.00 & & \\
\hline Bronchial wash & 15 & 164 & 0.26 & & \\
\hline BAL & 10 & 79 & 0.59 & & \\
\hline TBLB & 28 & 93 & 0.00 & 0.00 & $10.40(4.18-25.90)$ \\
\hline Use of midazolam & 22 & 213 & 0.10 & 0.01 & $0.31(0.14-0.73)$ \\
\hline Use of pethidine & 32 & 259 & 0.75 & & \\
\hline Use of atropine sulfate & 30 & 231 & 0.61 & & \\
\hline
\end{tabular}

Bold indicates statistical significance

$A M L$ Acute myeloid leukemia, BAL Bronchoalveolar lavage, BMT Bone marrow transplantation;

MPAL Mixed phonotype acute leukemia, PBST Peripheral blood stem cell transplantation, TBLB Transbronchial lung biopsy

whereas use of midazolam reduced the risk. The reason why use of midazolam reduced the risk of hemoptysis is not clear, though we speculate that a comfortable procedure as a result of sedation with midazolam might play an important and protective role. On the other hand, platelet count $\leq 20 \times 10^{3} / \mu$ l and platelet transfusion were not risk factors. The NICE guideline from the British Thoracic Society note that bronchoscopies without biopsy could be safely performed in patients with platelet counts $>20 \times 10^{3} / \mu \mathrm{l}$ [11]. In our hospital, patients with platelet count $\leq 20 \times 10^{3} / \mu \mathrm{l}$ received platelet transfusion before bronchoscopy based on this guideline. Weiss et al. investigated bronchoscopies in 58 patients with thrombocytopenia and found complications in 7 (12\%) but the complications were serious in only 1 patient [12]. Faiz et al. surveyed 1711 bronchoscopies and found that platelet transfusion was performed in $90.6 \%$ of patients with platelet counts of $<10 \times 10^{3} / \mu \mathrm{l}$ and $55.5 \%$ with platelet counts of $10 \times 10^{3}$ to $<20 \times 10^{3} / \mu$ l [13]. Bleeding occurred in $1.1 \%$ of the bronchoscopies but platelet transfusion did not significantly reduce the risk.

This study had several limitations, stemming mainly from its retrospective single-center design. Furthermore, given that midazolam was started in the middle of the study period, we cannot rule out "time-window bias". In addition, not all patients with hematologic malignancies underwent bronchoscopy. In our hospital, severe disseminated intravascular coagulation and bleeding tendency were contraindication for bronchoscopies, but their definitions were not confirmed. And, the definition of desaturation, we used here, was an unconventional one.

\section{Conclusions}

Bronchoscopy is relatively safe in patients with malignant hematologic disorders provided that respiratory status is monitored carefully after the procedure. Caution and judicious use of sedatives may improve the patient's procedural tolerance and lower complications. TBLB should be performed with extreme caution in these patients.

\section{Abbreviations}

HSCT: Hematopoietic stem cell transplantation; AML: Acute myeloid leukemia; MDS: Myelodysplastic syndromes; TBLB: Transbronchial lung biopsy

\section{Acknowledgments}

No

Authors' contributions

HU; Conceptualization-Lead, Writing-original draft-Lead. TS; Data curationLead. AN; Formal analysis-Lead. NU; Methodology-Lead. MT; InvestigationLead. SM; Project administration-Lead. YT; Project administration-Supporting. KO; Resources-Lead. KM; Resources-Supporting. SH; Supervision-Lead. HT; Writing-review \& editing-Supporting. AM; Validation-Supporting. NM; Validation-Lead. MK; Visualization-Supporting. HA; Visualization-Lead. RT; Supervision-Supporting. YA-M; Funding acquisition-Lead. AW; Funding acquisition-Equal. ST; Writing-review \& editing-Supporting. KK; Writing-review \& editing-Lead. All authors read and approved the final manuscript.

\section{Funding}

Okinaka Memorial Institute for Medical Research (Tokyo, Japan) only financially supported this study, and didn't take any part in the design of the study, and collection, analysis, and interpretation of data and in writing this manuscript.

\section{Availability of data and materials}

The datasets used and/or analysed during the current study are available from the corresponding author on reasonable request.

Ethics approval and consent to participate

The institutional review board of Toranomon Hospital approved this study (No. 1845). Informed consent was obtained in the form of opt-out on the 
web-site. Japanese personal information protection law and guidelines for clinical research permitted opt-out method in retrospective study.

\section{Consent for publication}

Not applicable.

\section{Competing interests}

The authors have no potential conflict of interest related to this article.

\section{Author details}

${ }^{1}$ Department of Respiratory Medicine, Respiratory Center, Toranomon Hospital, Tokyo, Japan. ${ }^{2}$ Department of Respiratory Medicine, Toranomon Hospital Kajigaya, Kawasaki, Kanagawa, Japan. ${ }^{3}$ Okinaka Memorial Institute for Medical Research, Tokyo, Japan. ${ }^{4}$ Respiratory Center, KKR Sapporo Medical Center, Sapporo, Japan. ${ }^{5}$ Department of Hematology, Toranomon Hospital, Tokyo, Japan. 'Department of Hematology, Toranomon Hospital Kajigaya, Kawasaki, Kanagawa, Japan. ${ }^{7}$ Department of Infectious Diseases, Toranomon Hospital, Tokyo, Japan. ${ }^{8}$ Department of Respiratory Medicine, Toho University Omori Medical Center, Tokyo, Japan.

Received: 23 March 2020 Accepted: 7 September 2020

\section{Published online: 11 September 2020}

\section{References}

1. Patel NR, Lee PS, Kim JH, Weinhouse GL, Koziel H. The influence of diagnostic bronchoscopy on clinical outcomes comparing adult autologous and allogeneic bone marrow transplant patients. Chest. 2005;127:1388-96.

2. Nishio JN, Lynch JP 3rd. Fiberoptic bronchoscopy in the immunocompromised host: the significance of a "nonspecific" transbronchial biopsy. Am Rev Respir Dis. 1980;121:307-12.

3. Phillips MJ, Knight RK, Green M. Fibreoptic bronchoscopy and diagnosis of pulmonary lesions in lymphoma and leukaemia. Thorax. 1980;35:19-25.

4. Williams D, Yungbluth M, Adams G, Glassroth J. The role of fiberoptic bronchoscopy in the evaluation of immunocompromised hosts with diffuse pulmonary infiltrates. Am Rev Respir Dis. 1985;131:880-5.

5. Azoulay E, Mokart D, Pène F, Lambert J, Kouatchet A, Mayaux J, et al. Outcomes of critically ill patients with hematologic malignancies: prospective multicenter data from France and Belgium--a groupe de recherche respiratoire en reanimation onco-hematologique study. J Clin Oncol. 2013:31:2810-8.

6. Harris B, Lowy FD, Stover DE, Arcasoy SM. Diagnostic bronchoscopy in solidorgan and hematopoietic stem cell transplantation. Ann Am Thorac Soc. 2013;10:39-49

7. Yanik GA, Ho VT, Levine JE, White ES, Braun T, Antin JH, et al. The impact of soluble tumor necrosis factor receptor etanercept on the treatment of idiopathic pneumonia syndrome after allogeneic hematopoietic stem cell transplantation. Blood. 2008:112:3073-81.

8. Crawford M, Pollock J, Anderson K, Glavin RJ, MacIntyre D, Vernon D. Comparison of midazolam with propofol for sedation in outpatient bronchoscopy. Br J Anaesth. 1993;70:419-22.

9. Rolo R, Mota PC, Coelho F, Alves D, Fernandes G, Cunha J, et al. Sedation with midazolam in flexible bronchoscopy: a prospective study. Rev Port Pneumol. 2012;18:226-32.

10. Contoli M, Gnesini G, Artioli D, Ravenna C, Sferra S, Romanazzi C, et al. Midazolam in flexible bronchoscopy premedication: effects on patientrelated and procedure-related outcomes. J Bronchology Interv Pulmonol. 2013;20:232-40.

11. Du Rand IA, Barber PV, Goldring J, Lewis RA, Mandal S, Munavvar M, et al. British Thoracic Society guideline for advanced diagnostic and therapeutic flexible bronchoscopy in adults. Thorax. 2011:66:iii1-21.

12. Weiss SM, Hert RC, Gianola FJ, Clark JG, Crawford SW. Complications of fiberoptic bronchoscopy in thrombocytopenic patients. Chest. 1993;104:1025-8.

13. Faiz SA, Jimenez CA, Fellman BM, Huk $T$, Jazbeh $S$, Haque $S A$, et al. Incidence of bleeding complications with flexible bronchoscopy in Cancer patients with thrombocytopenia. J Bronchology Interv Pulmonol. 2019;26:280-6.

\section{Publisher's Note}

Springer Nature remains neutral with regard to jurisdictional claims in published maps and institutional affiliations.

Ready to submit your research? Choose BMC and benefit from:

- fast, convenient online submission

- thorough peer review by experienced researchers in your field

- rapid publication on acceptance

- support for research data, including large and complex data types

- gold Open Access which fosters wider collaboration and increased citations

- maximum visibility for your research: over $100 \mathrm{M}$ website views per year

At BMC, research is always in progress.

Learn more biomedcentral.com/submissions 